\title{
Three Point Bend Creep Testing of Carbon/Epoxy
}

David S. Hiromoto

Materials Test and Evaluation Section

Engineering Sciences Division

June 27,1990

This is an informal report intended primarily for internal or limited external distribution. The opinions and conclusions stated are those of the author and may or may not be those of the Laboratory.

Work performed under the auspices of the U.S. Department of Energy by the

Iawrence livermore National laboratory under Contract W-7405-Eng-48. 
This document was prepared as an account of work sponsored sy an agency of the United States Government. Neither the United States Government nor the University of California nor any of their employeer, makes any warranty, express or implied, or assumes any legal liability or responsibility for the accuracy, completeness, or usefulness of any information, apparatus, product, or process disclosed, or represents that its use would not infringe privately owned rights. Reference herein to any specific commercial products, proress, or service by trade name, trademark, manufacturer, or otherwise, does not necessarily constitute or imply its endorsement, recommendation, or favoring by the United States Government or the University of California. The views and opinions of authors expressed herein do not necessarlly state or reflect those of the Uniled States Government or the University of California, and shall not be used for advertising or product endorsement purposes.

$$
\begin{aligned}
& \text { This report has been reproduced } \\
& \text { directly from the best avalable copy. }
\end{aligned}
$$

Avallable to DOE and DOE contractors irum the Office of Sicientific and Technical Information 1.0. Hox 62, Oak Ridge, TN 37831

Prices available from (615) 576-8401, FTS 626.6401.

Avallable to the public from the Natlonal Technical Information Service

U.S. Department of Commerce 5285 Porl Ruyal Rd. Springfield, VA 22161

Price

Code

A01

\section{Papercopy Prices}

A.02

$\mathrm{A} 03$

A04

A05

A.06

A07

A08

A09

A10

A11

A12

A13

A14

A15

A16

A17

A18

A19

A20

A21

A22

A23

A24

A 25

A.99
Page

Range

Microfiche 
Three Point Bend Creep Testing of Carbon/Epoxy

David S. Hiromoto

Materials Test and Evaluation Section

Engineering Sciences Division

\begin{abstract}
This study provides data to verify theoretical models for predicting and characterizing viscoelastic behavior of fiber composites. Since performing uninterrupted creep tests for years at a time was not feasible, creep behavior was accelerated with elevated temperatures.

An improved method was developed and implemented for measuring specimen deflection within the tight confines of an environmental chamber. This proved to be critical to make this experiment a success.
\end{abstract}




\section{Three Point Bend Creep Testing of Carbon/Epoxy \\ David S. Hiromoto \\ Materials Test and Evaluation Section \\ Engineering Sciences Division}

Introduction

Dimensional stability of materials is critical for structural applications. Many new applications for fiber composite materials, i.e., carbon/epoxy, are being implemented in high technology industries. As the need for these materials grow more data will be required to predict long-term behavior. This study, funded by the Mechanical Engineering Research, supplies data to verify theoretical models for predicting viscoelastic (creep) behavior.

\section{Test Specimens}

Carbon/epoxy panels were fabricated by the Composites Fabrication Group of Materials Fabrication Division. The material used for this study is a carbon fiber tape, TC2145, preimpregnated with epoxy resin, Hexcel F263 (also termed as pre-preg). F263 resin was chosen because of the extensive data available to help verify theoretical models.

Coupons were cut to approximately $4.50 "$ long, $.500 "$ wide, and approximately $.080 "$ thick.

\section{Eiber Orientation}

Panel 1 - All $0^{\circ}$ or $90^{\circ}$

Panel $2-\left(+45^{\circ} /-45^{\circ}\right) 8$ symmetrical

Panel 3 - $(0,-45,90,+45) 4$ symmetrical (termed Quasi-Isotropic)

Each panel had 16 total plies and an average thickness of approximately .080".

\section{Test Apparatus and Procedure}

Environmental chambers with elevated temperature capability and controlled loading were used for the experiment. Hallikainen temperature controllers were used to maintain temperatures up to $250^{\circ} \mathrm{F}$ at $\pm 1^{\circ}$. Elevated temperatures were used to accelerate creep behavior and see trends which would otherwise take months or years at ambient temperatures.

Because of their thermal stability, portability, and resistance to air turbulence, Bourn's potentiometers were used to measure specimen deflection for three point bend tests.

Test fixturing for three point bend creep tests was designed by the author (Figure 1). The loading of specimens was controlled by a motor driven cross head (which supported dead weights) to assure uniformity of tests (Figure 2). Most tests lasted five to seven days.

An IBM PC coupled with a HP3497A Data Acquisition control unit were used to take the data from potentiometers and thermocouples. Once these tests were completed, data was converted to Apple Macintosh format and plotted using Kaleidagraph software. 


\section{Results/Summary}

Results in the table (shown in figure 3) show the test I.D. number, the orientation of fibers in each specimen, test temperature, and load. Specimen dimensions, span, and approximate deflection measured 1.0" off center are also listed.

Initially, the same test fixturing was used to measure deflection, but using and indirect measurement technique. This tended to lack repeatability, and modification of measuring technique seemed to be the answer. Instead of measuring indirectly and using crosshead as a reference, the transducer (Bourn's potentiometer) was moved inside the horizuntal beam of the fixture and (lightly) spring loaded to be in direct contact with the 3 point bend specimens. Repeatability and accuracy were significantly improved and made the experiment a success.

Ideally, higher temperatures would have been used to increase acceleration of creep except $250^{\circ} \mathrm{F}$ was the maximum our Bourn's potentiometers could handle. However, sufficient creep was noted to verify theoretical models for predicting creep beivavior.

\section{Acknowledgement}

I would like to thank Dr. William W. Feng for his valuable contributions to make these tests a success.

\section{Eigures}

1. Three Point Bend Fixture.

2. Environmental Chamber, Loading AT raratus, and Data Acquisition System.

3. Three point Bend Creep Test summ ary. 


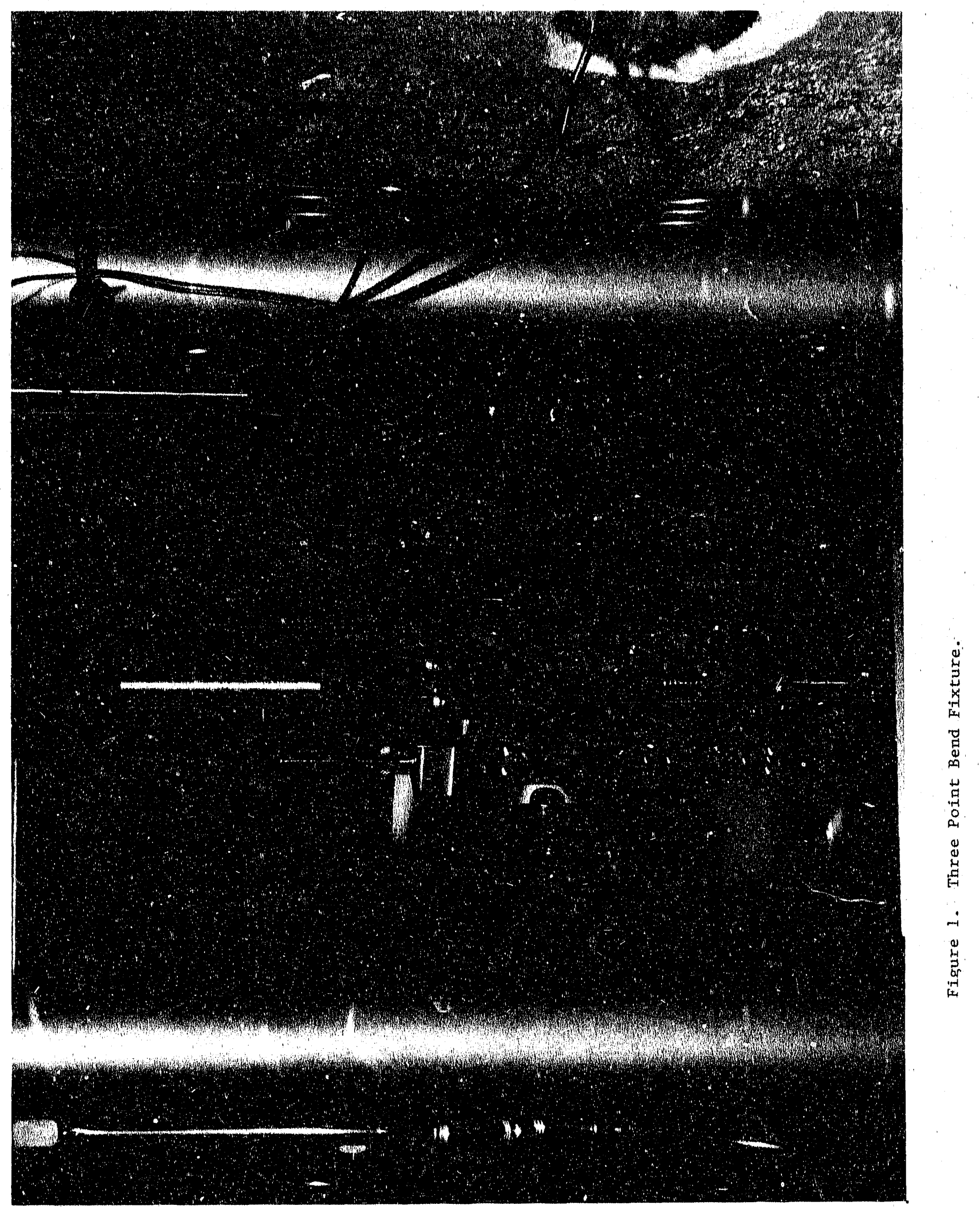




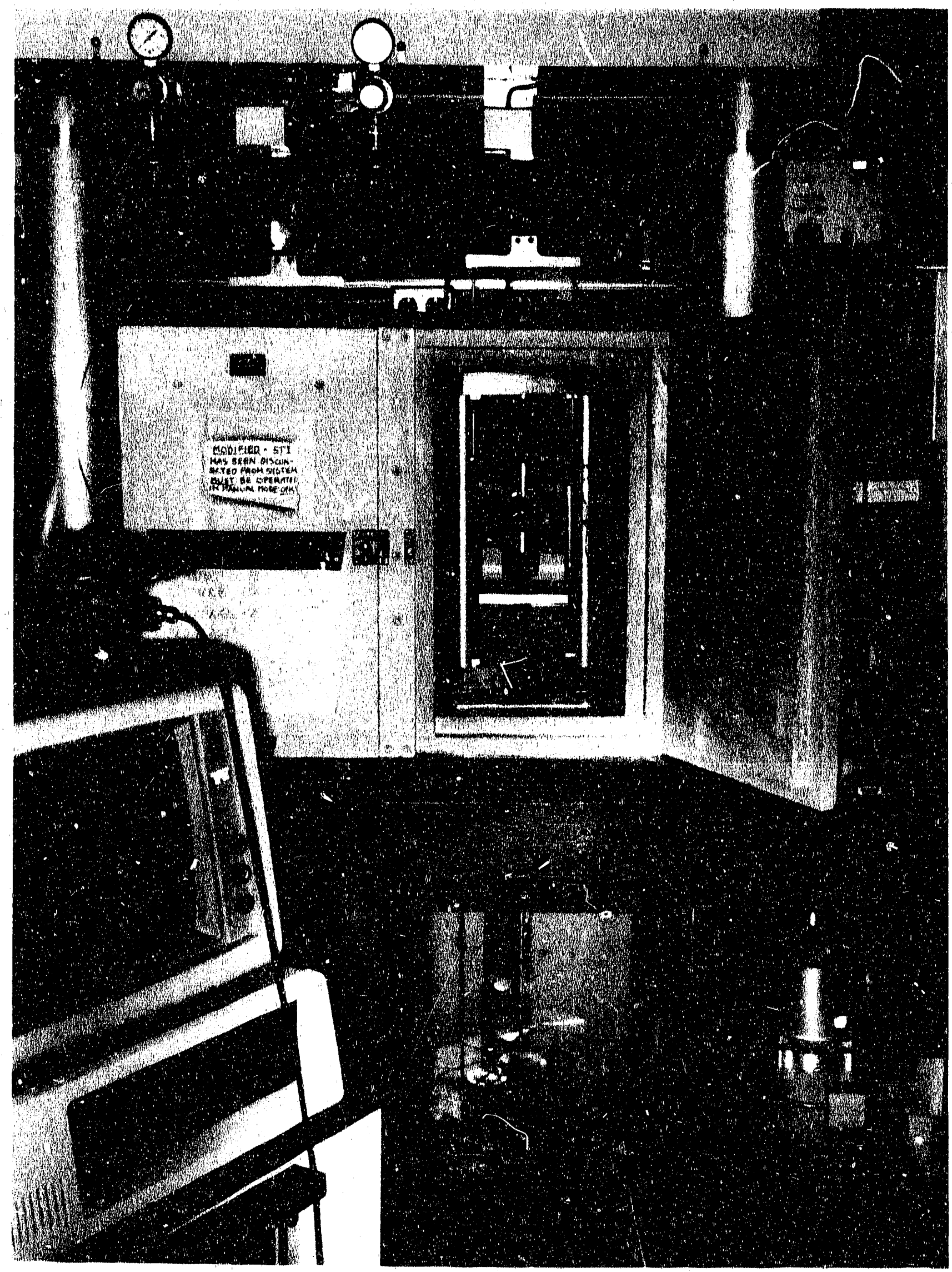

Flgure 2. Environmeital Chamber, Loading Apparatus, and Data Acquisition System. 


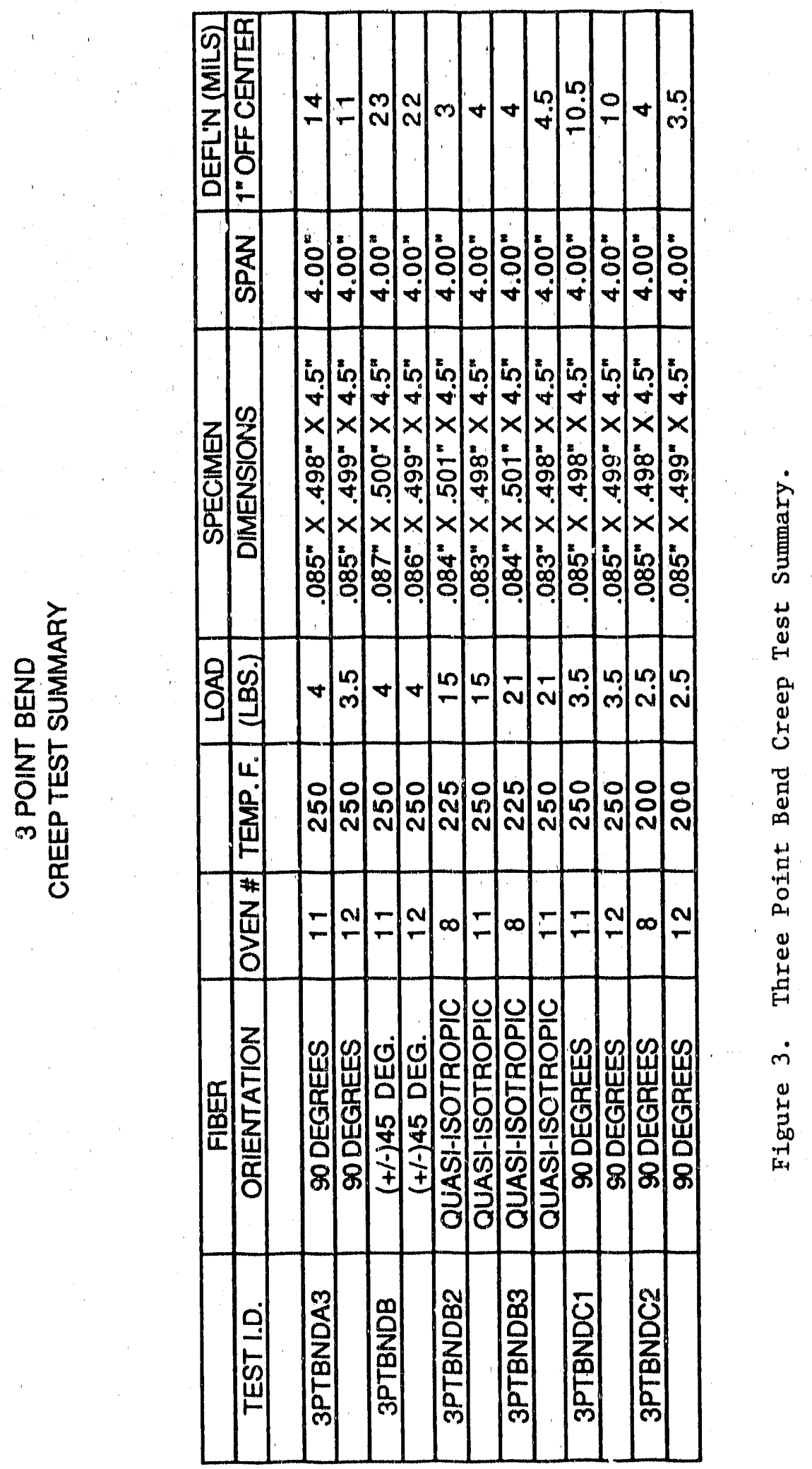




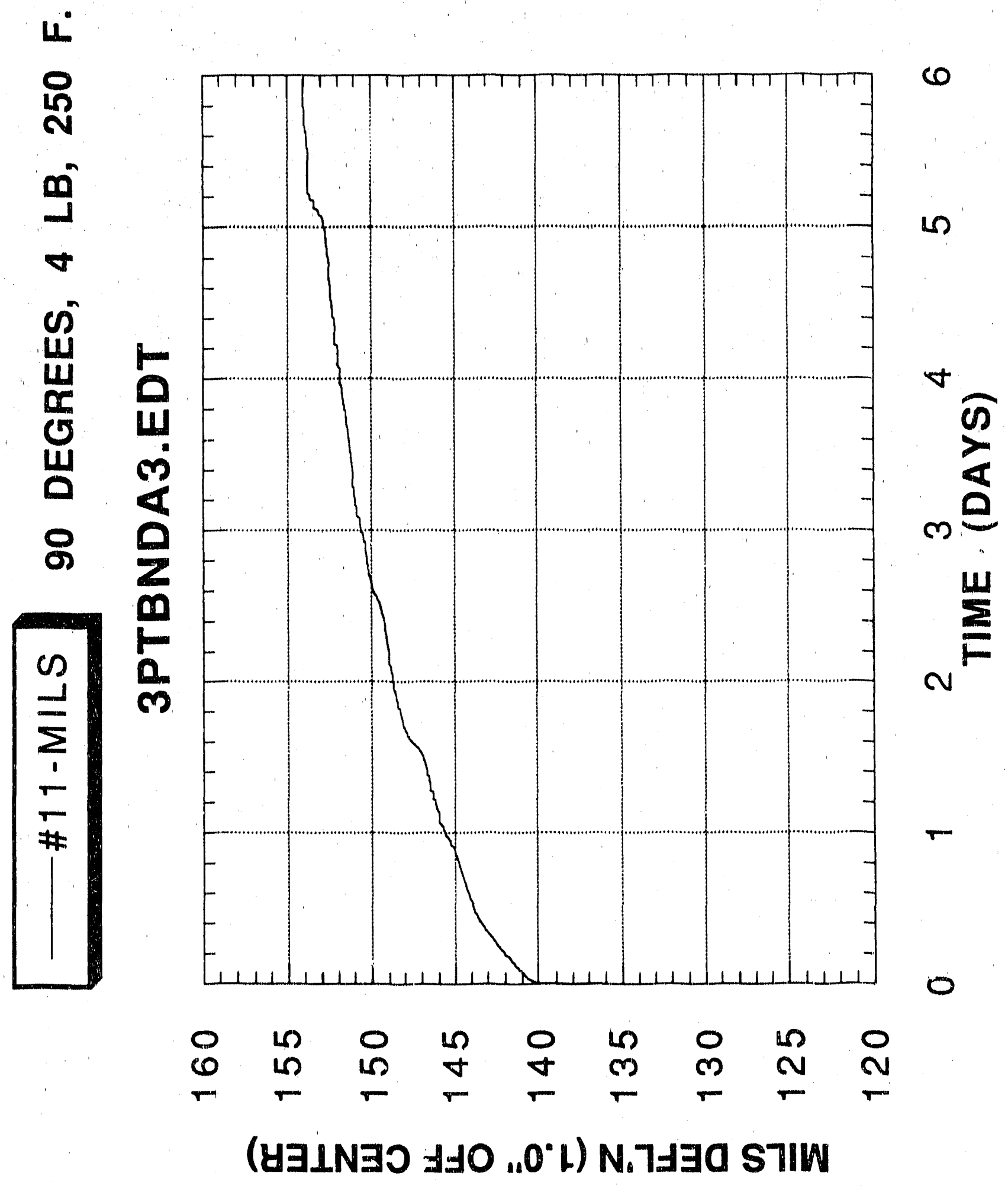




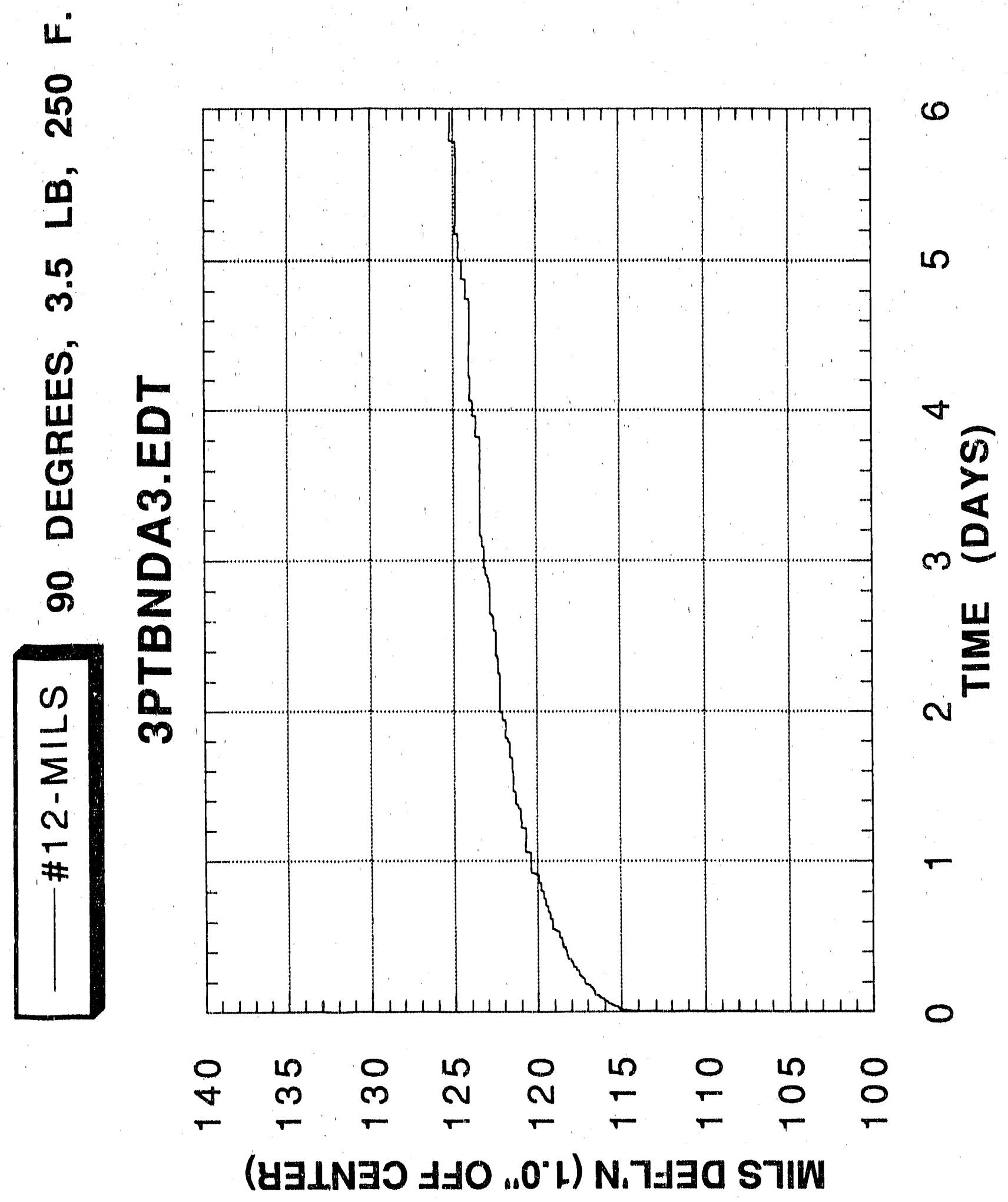




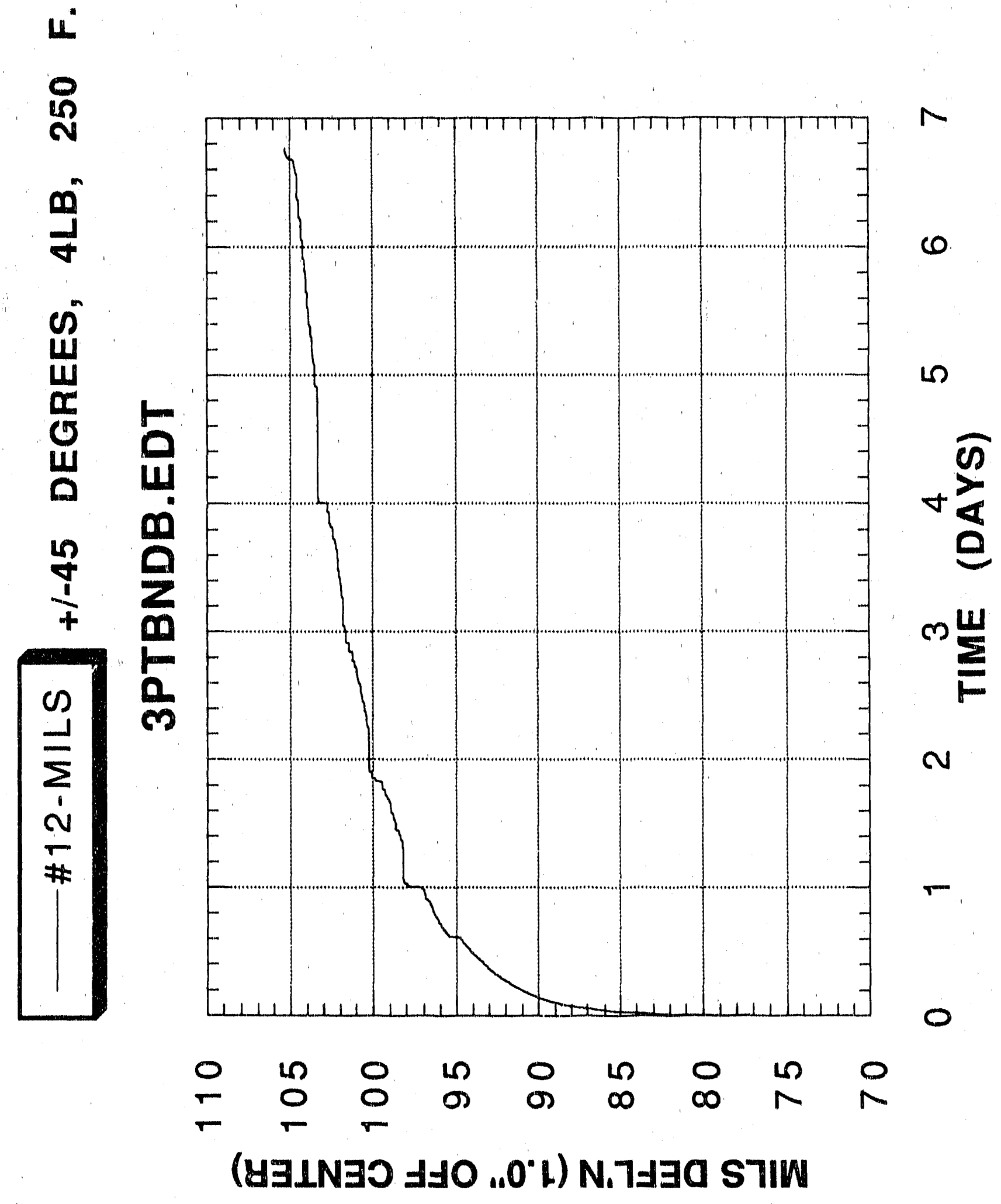




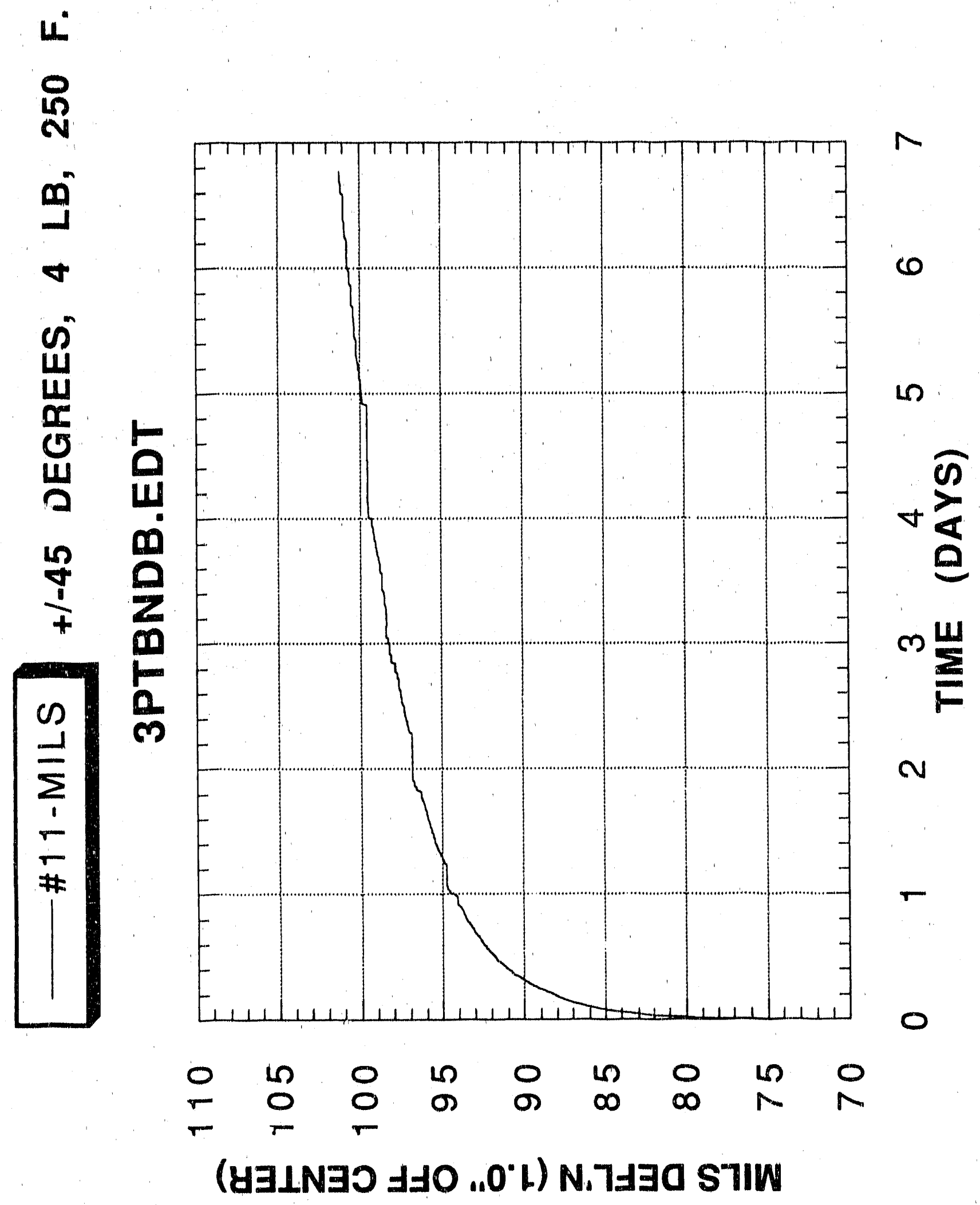




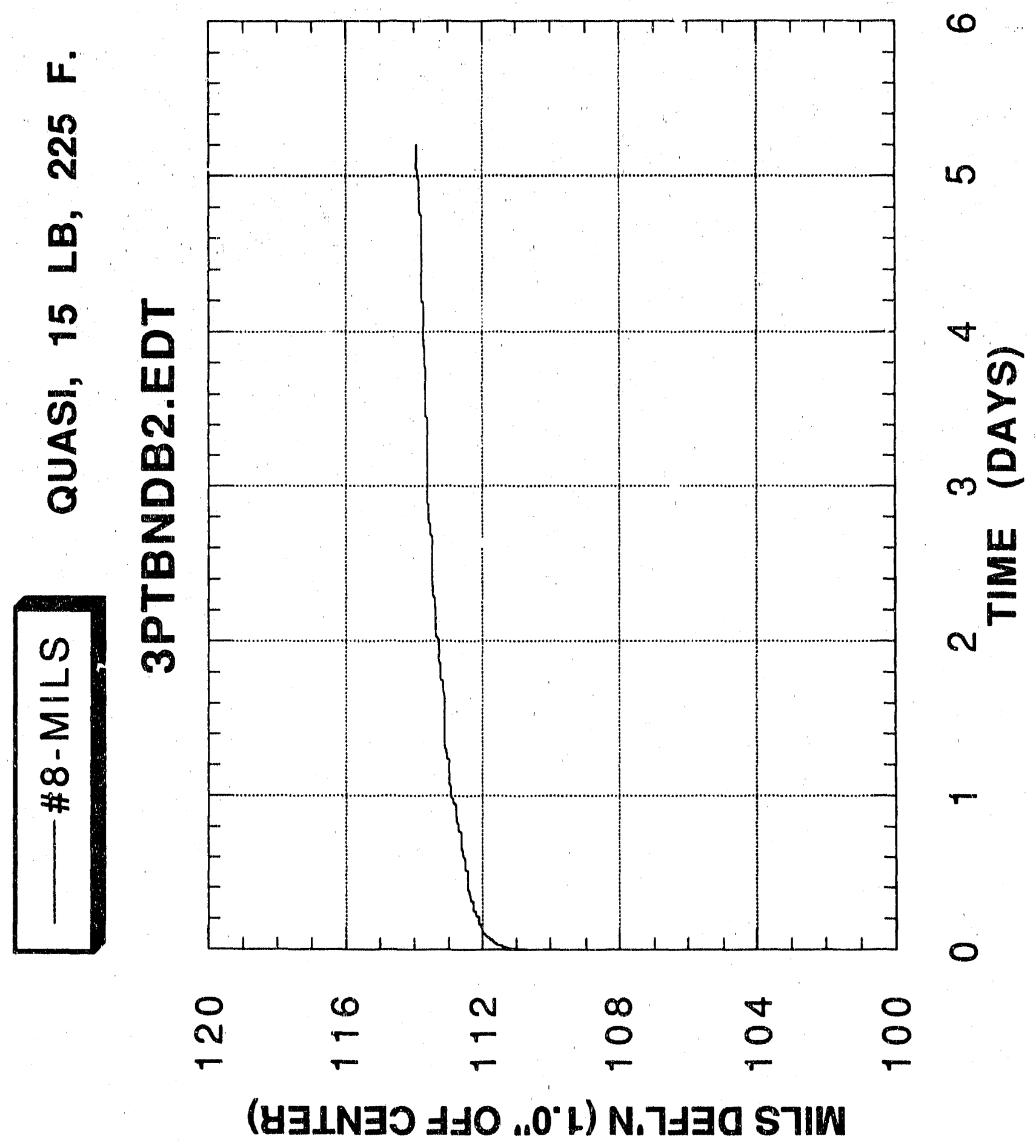




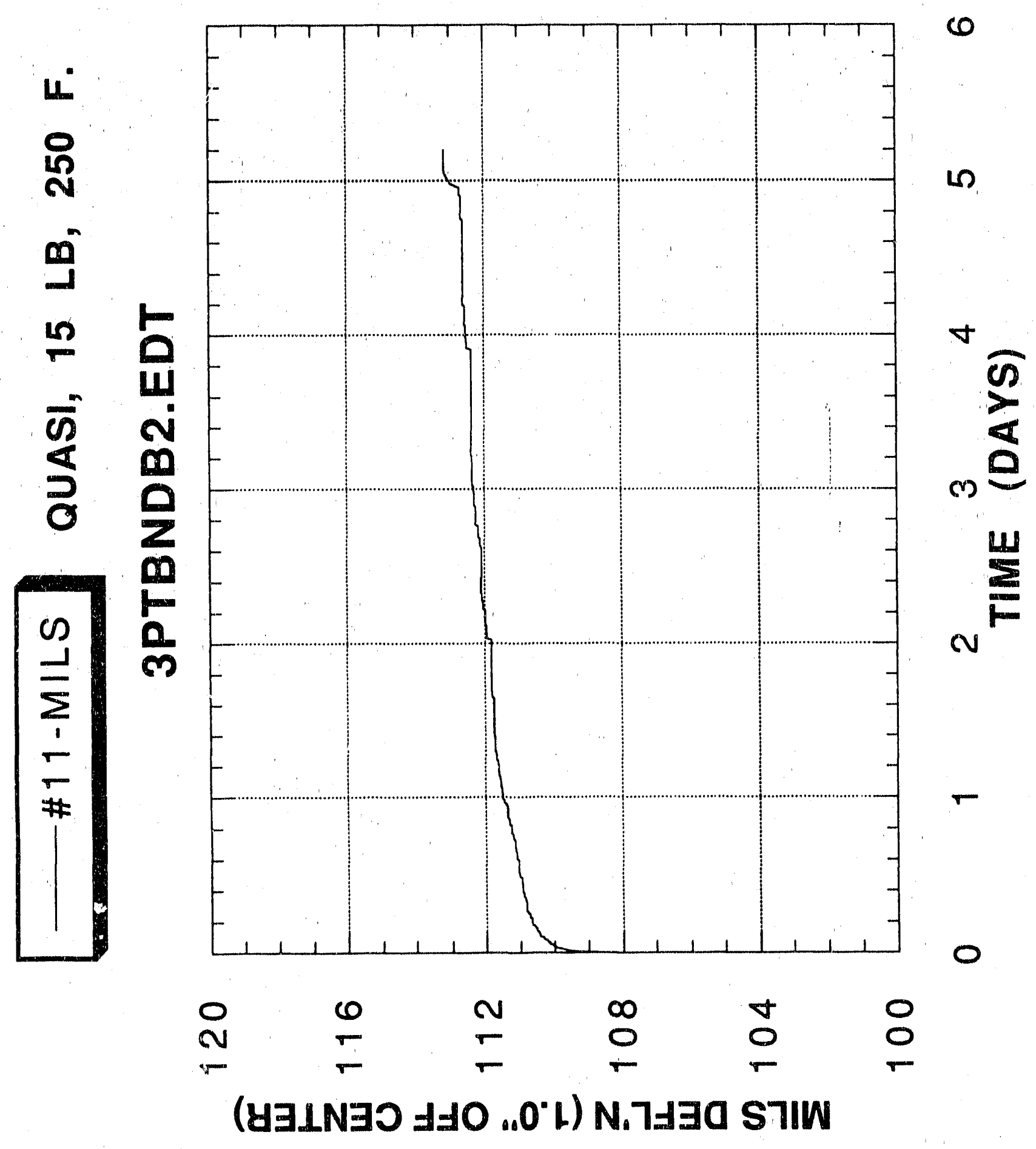




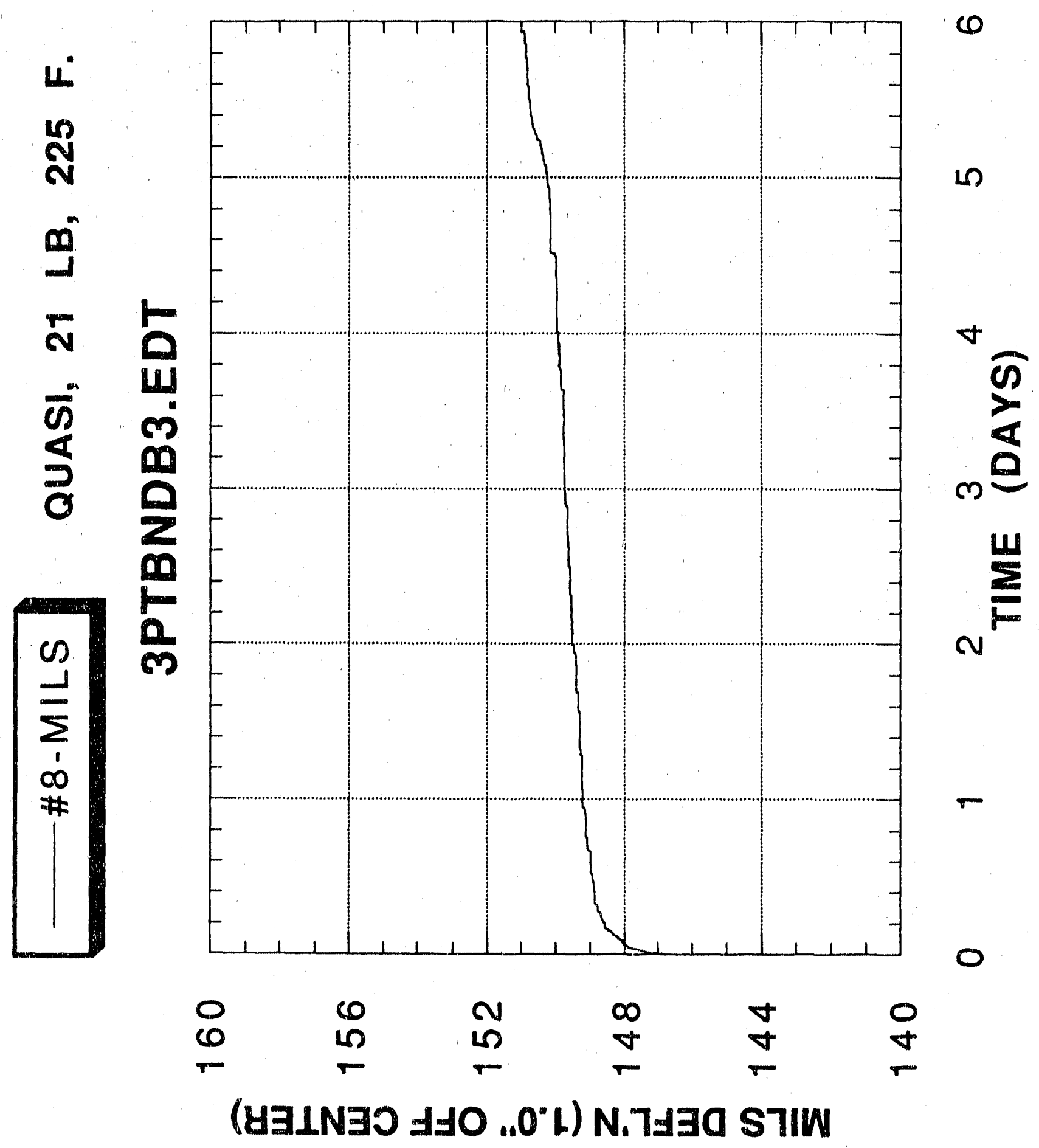




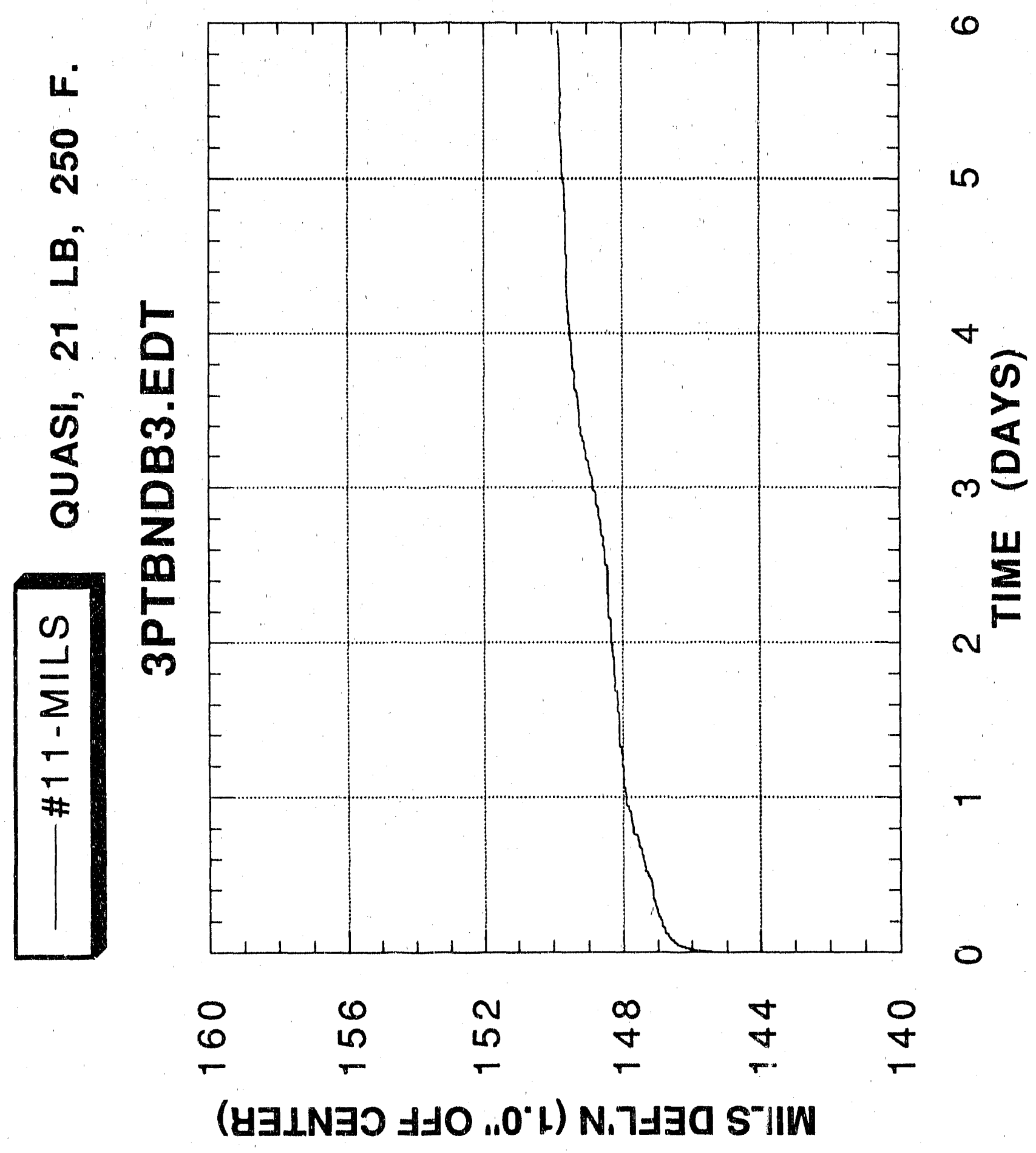




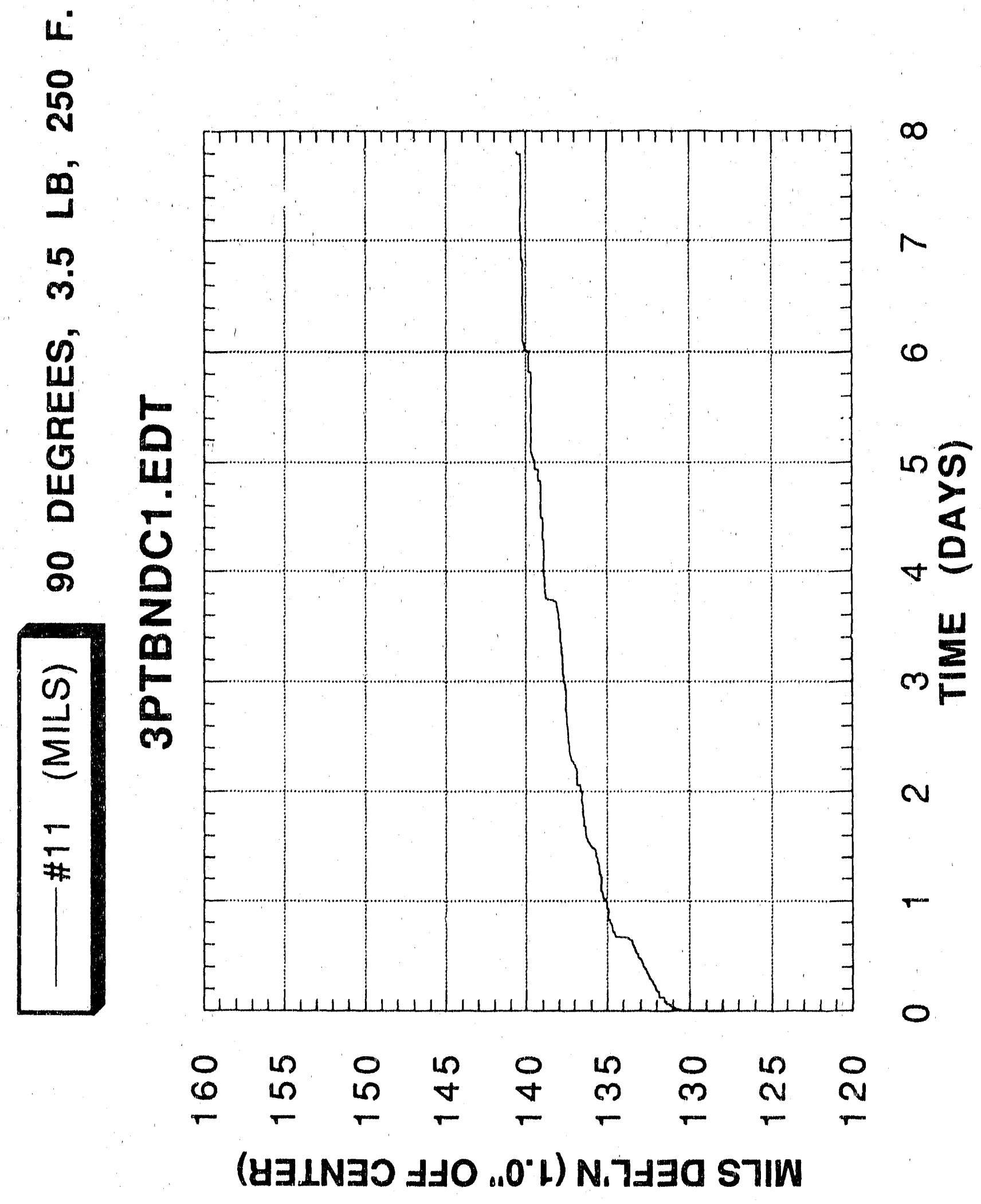




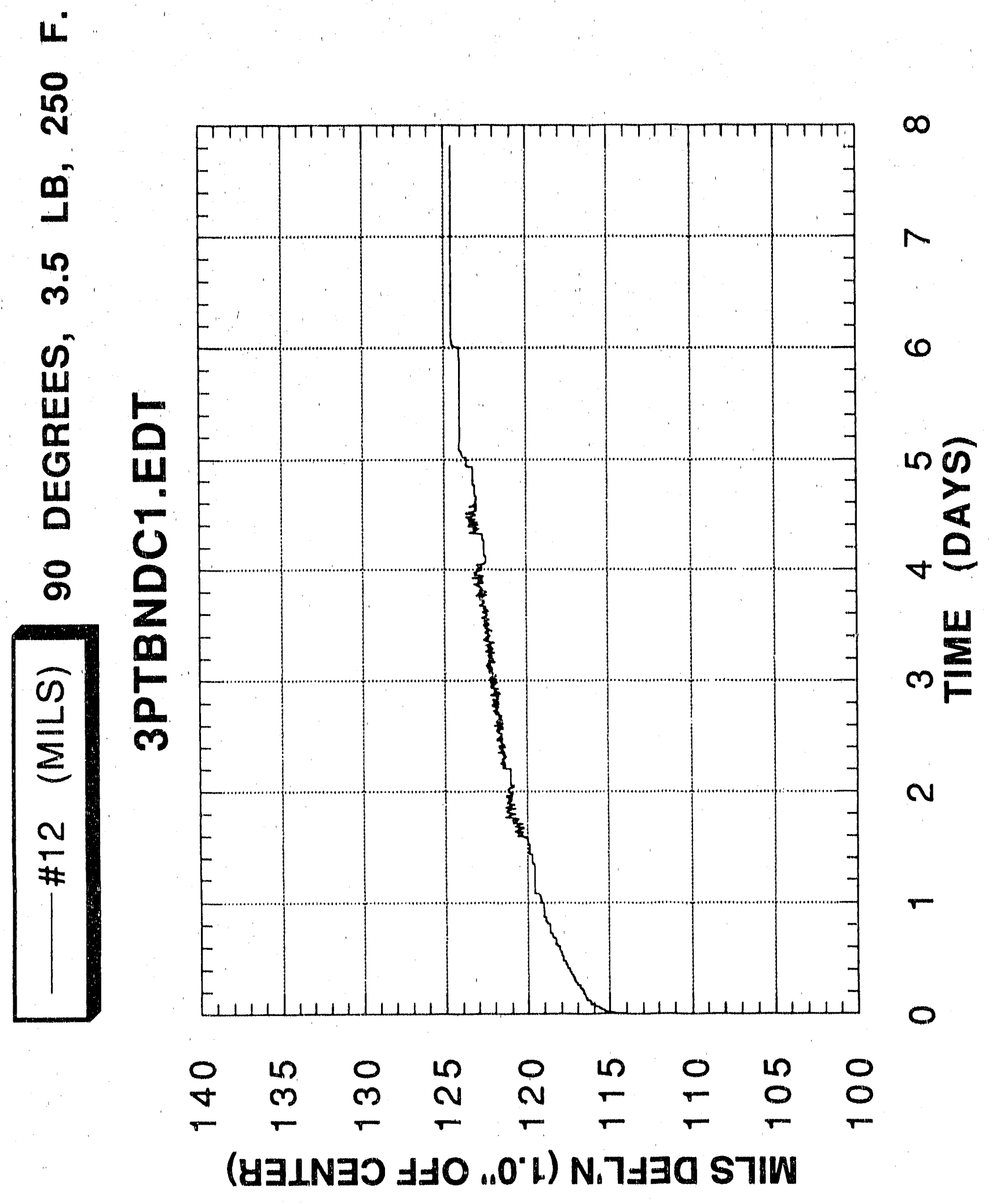




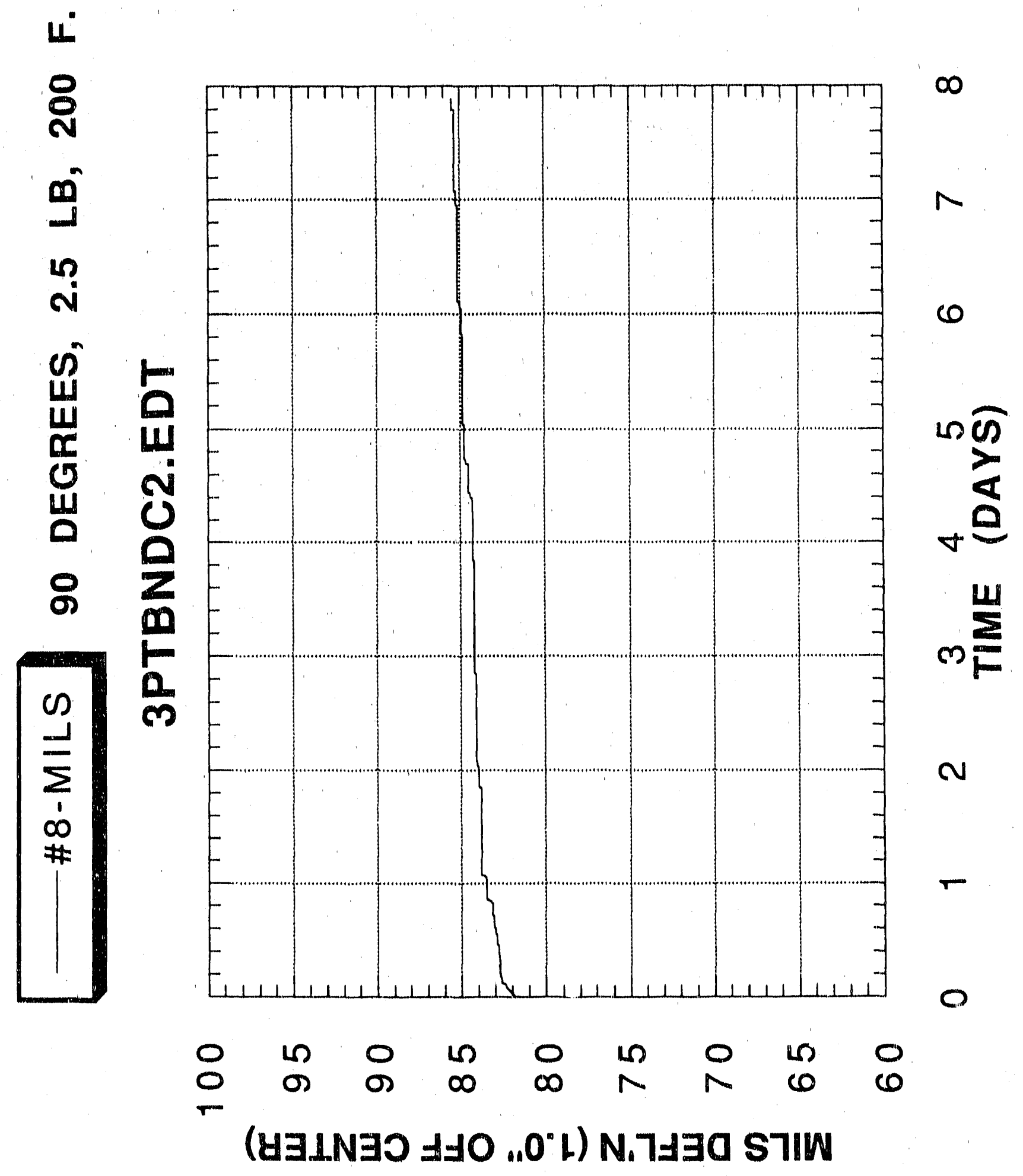




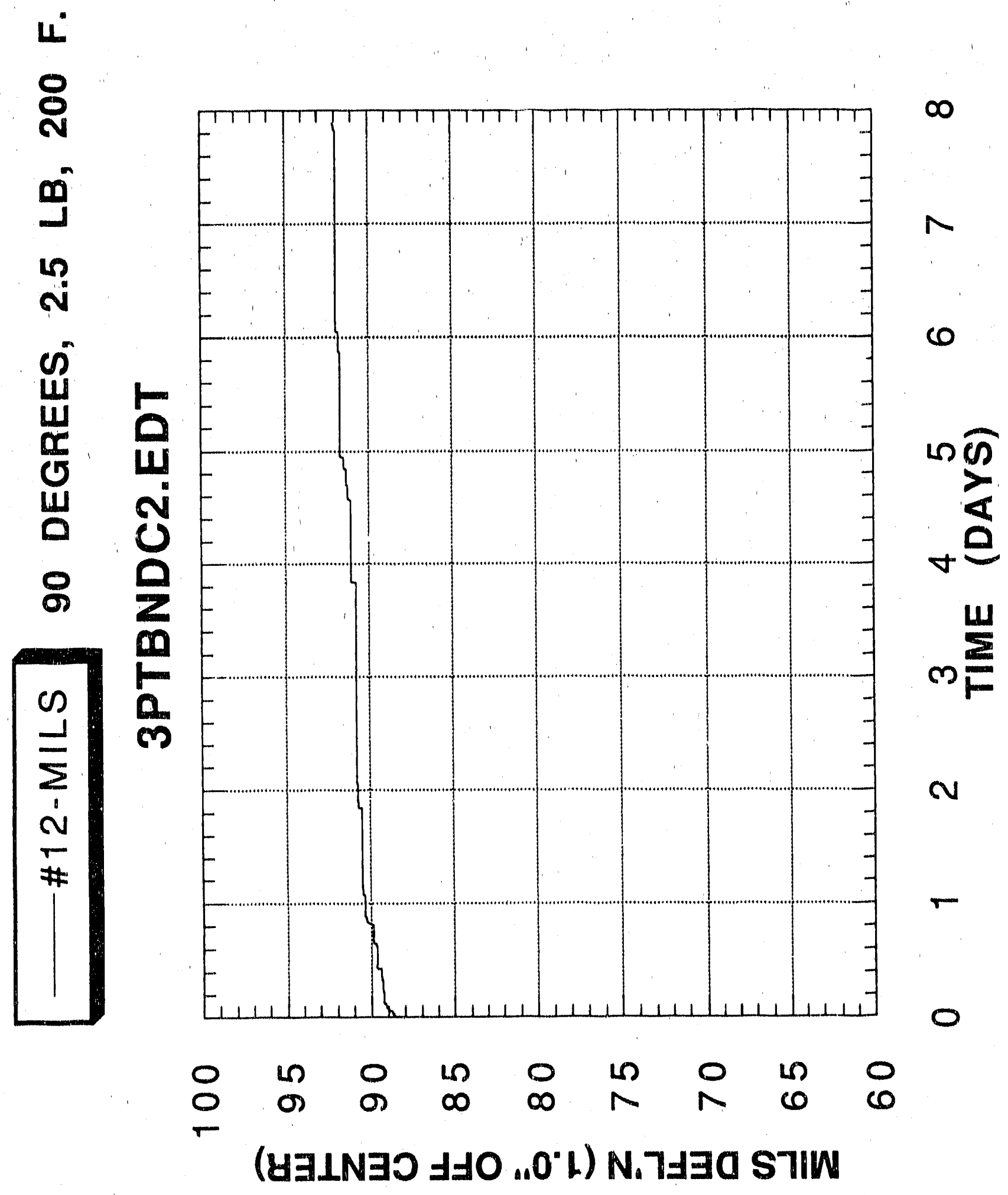



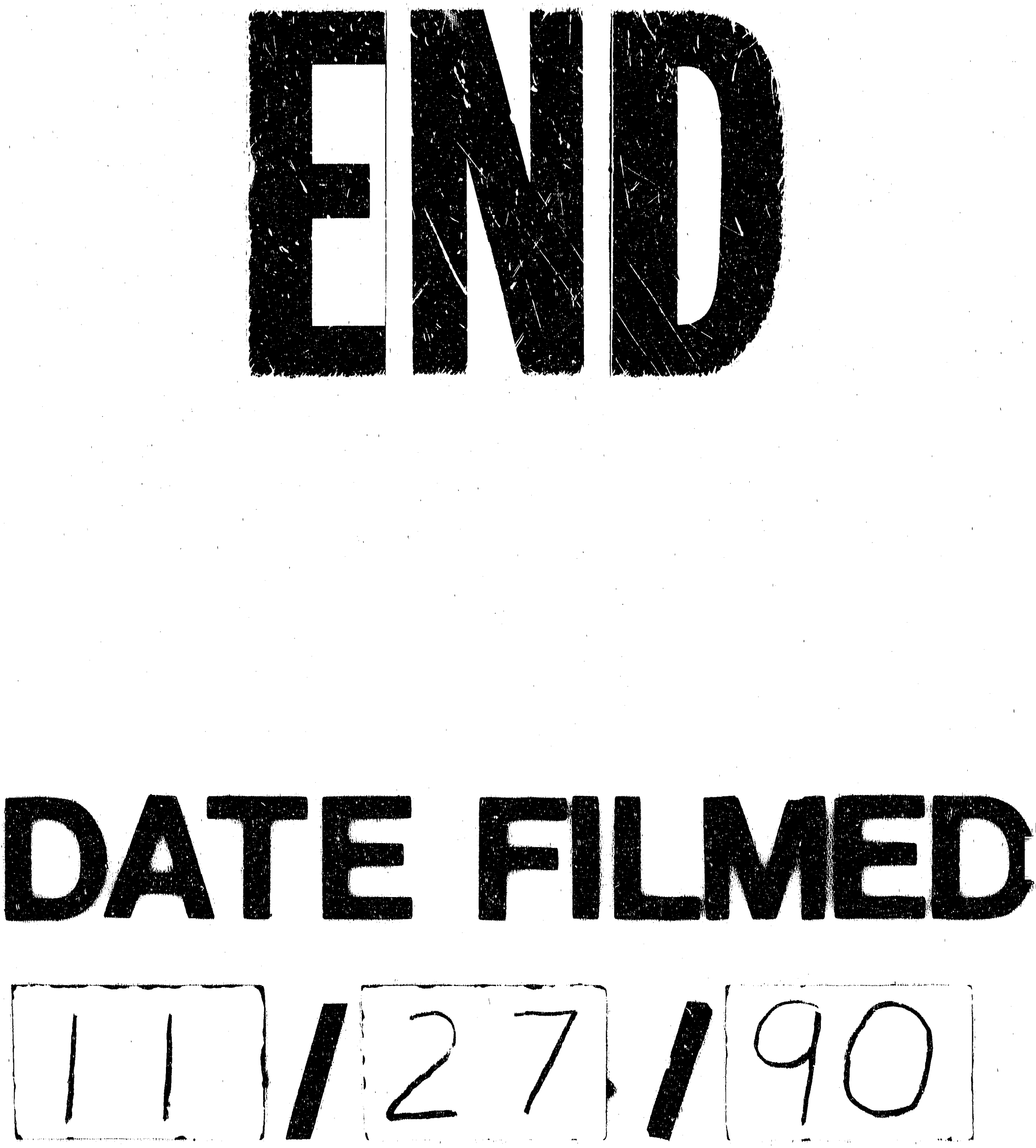
